\title{
Dutch national scientific research program on land subsidence: Living on soft soils - subsidence and society
}

\author{
Esther Stouthamer ${ }^{1}$, Gilles Erkens ${ }^{7,1}$, Kim Cohen $^{1}$, Dries Hegger $^{2}$, Peter Driessen ${ }^{2}$, \\ Hans Peter Weikard ${ }^{6}$, Mariet Hefting ${ }^{4}$, Ramon Hanssen ${ }^{5}$, Peter Fokker ${ }^{8}$, Jan van den Akker ${ }^{9}$, \\ Frank Groothuijse ${ }^{3}$, and Marleen van Rijswick ${ }^{3}$ \\ ${ }^{1}$ Department of Physical Geography, Utrecht University, Princetonlaan 8A, 3584 CB Utrecht, the Netherlands \\ ${ }^{2}$ Copernicus Institute of Sustainable Development, Utrecht University, Princetonlaan 8A, \\ 3584 CB Utrecht, the Netherlands \\ ${ }^{3}$ Utrecht University, Centre for Water, Oceans and Sustainability Law, Newtonlaan 201, \\ 3584 BH Utrecht, the Netherlands \\ ${ }^{4}$ Department of Environmental Biology, Utrecht University, Padualaan 8, 3584 CH Utrecht, the Netherlands \\ ${ }^{5}$ Faculty of Civil Engineering, Delft University of Technology, 2628 CD Delft, the Netherlands \\ ${ }^{6}$ Department of Social Sciences, Wageningen University, Hollandseweg 1, \\ $6706 \mathrm{KN}$ Wageningen, the Netherlands \\ ${ }^{7}$ Deltares Research Institute, Daltonlaan 600, 3584 BK Utrecht, the Netherlands \\ ${ }^{8}$ TNO-Geological Survey of The Netherlands, Princetonlaan 6, 3584 CB Utrecht, the Netherlands \\ ${ }^{9}$ Wageningen Environmental Research, Droevendaalsesteeg 3, 6708 PB Wageningen, the Netherlands
}

Correspondence: Esther Stouthamer (e.stouthamer@uu.nl)

Published: 22 April 2020

\begin{abstract}
In the Netherlands land subsidence is a continuously ongoing process. Consequently, an increasing number of people and economic assets are exposed to subsidence, damage costs are soaring, and flood risk and greenhouse gas emissions are increasing. In some areas tipping points have already been reached, where current land-use can no longer be maintained without considerable costs, underlining the urgency to take action.

Together with a consortium consisting of universities, research institutes, governmental agencies, public and private partners we have developed a national, multidisciplinary research programme aiming to develop an integrative approach to achieve feasible, legitimate and sustainable solutions for managing the negative societal effects of land subsidence, connecting fundamental research on subsidence processes to socio-economic impact of subsidence and to governance and legal framework design.

The program is designed to co-create insights that help to effectively mitigate and adapt to subsidence within the Netherlands by making major improvements in measuring and modeling the processes and consequences of subsidence, identifying, developing and critically evaluating control measures and designing governance and legal approaches that facilitate their implementation. Hereto we will develop (a) new satellite-based technology to measure, attribute and monitor subsidence, (b) solid understanding of the interacting multiple processes contributing to total subsidence, (c) sophisticated physical and economic numerical models to predict humaninduced subsidence rates and impacts, and (d) implementation strategies that go beyond technical measures, to strengthen governance and financing capacities as well as legal frameworks. This fully integrated approach deals with all impacts of land subsidence on society and the economy.
\end{abstract}




\section{Land subsidence in the Netherlands}

In the Netherlands land subsidence is a continuously ongoing process due to (1) drainage of peatlands and areas reclaimed from the sea, (2) expansion of built-up areas and the infrastructural network on soft soil, (3) salt mining and gas extraction (Fig. 1). These human-induced drivers result in relatively high rates of subsidence $\left(\sim 0.5-10 \mathrm{~cm} \mathrm{yr}^{-1}\right.$. An increasing number of people and economic assets are exposed to subsidence and damage costs are soaring, accumulating to over EUR 5 billion for infrastructure alone till 2050 (Van den Born et al., 2016). Moreover it gives rise to serious safety issues due to increased flood risks and in case of subsidence as a result of peat oxidation - causes considerable greenhouse gas (GHG)emissions which will further contribute to climate change. Because the shallow subsurface of $\sim 50 \%$ of the Netherlands and $\sim 80 \%$ of the low lying western and northern part contains organic material (peat and organic clay) (Koster et al., 2018), subsidence rates will increase further due to climate change ( $>$ oxidation and GHG emission). In some areas (e.g. parts of polder GrootMijdrecht, Zuidplaspolder) tipping points have already been reached, where current land use can no longer be maintained without considerable costs, underlining the urgency to take action.

During the last decades a range of mitigation and adaptation measures have been developed, however these are mostly ad-hoc applied local measures in response to incidents. This is caused by the fact that there is still little understanding of the exact rates and processes causing subsidence. That makes that timeliness of implementing measures and their effectiveness are hard to assess by land owners and responsible authorities, stalling implementation of measures at the large scale on which the problem is occurring. The implementation of measures for mitigating or adapting to land subsidence poses governance, economic and legal challenges. Mitigating measures may to some extent enable the continuation and reconciliation of certain land-use functions such as agriculture and nature conservation, but this is not without limits. At some point political choices might need to be made that deviate drastically from existing and historical policies and impact numerous interests and stakeholders.

Subsidence and GHG emissions can be mitigated by smart and efficient management strategies regarding e.g. spatial planning, extraction of hydrocarbons and groundwater, groundwater tables, and land use. However, this requires thorough knowledge on the (interacting) processes causing subsidence, its impacts and possible integrated solutions.

\section{National scientific research program}

The threat of land subsidence, the knowledge hiatus on process-interplays causing it, and lacking mid- to long-term coping strategies, ask for an integrated research program that addresses the issue of land subsidence in a holistic way, whereby insights about physical-chemical-biological system functioning, development, evaluation and implementation of measures as well as an assessment of their governance and legal implications co-evolve.

Therefore, together with a consortium consisting of 3 universities (Utrecht University, Delft University of Technology, Wageningen University), research institutes (Deltares, TNOGeological Survey of The Netherlands, Wageningen Environmental Research), governmental agencies, public and private partners we have developed a national, multidisciplinary research programme (runtime: 2020-2024) aiming to develop an integrative approach to achieve feasible, legitimate and sustainable solutions for managing the negative societal effects of land subsidence, connecting fundamental research on subsidence processes to socio-economic impact of subsidence and to governance and legal framework design. The program is to contribute significantly to the ability to mitigate and adapt to subsidence in populated, governed deltas in the short and in the long term and via management of subsidence, lower GHG emissions and decrease risks and looming damage for low-lying delta plains under climate change.

\subsection{Program objectives}

The underlying scientific challenges and objectives of this program are to:

1. tailor latest satellite-based radar technology to measure and monitor ground movement at high spatio-temporal resolutions, integrate this with inverse-modelling techniques to disentangle total shallow and deep subsidence, anthropogenic and natural contributions, and offer conscious choices when recombining the geophysically separated components in subsidence projections (spatial forecasts);

2. understand and quantify all mechanisms causing subsidence and associated GHG emission currently at play in the Netherlands, with attention to interrelationships and process-separation uncertainties, offering models of the processes affecting the aerated topsoil and actively consolidating subsoil, which are calibrated at experiment plot scale and recalibrated to coarser cell-scales of the spatial forecasts;

3. develop a set of reliable, alternative-scenario-sensitive spatial forecasts for actual and projected subsidence rates, including modules that convert subsidence rates $\left(\mathrm{mm} \mathrm{yr}^{-1}\right)$ to costs (EUR yr$\left.{ }^{-1}\right)$ and use these as operational tools to develop strategies to convey results of cost-benefit analyses to decision makers. The step to costs (pricing) requires to develop algorithms to (i) account for risk of structure-failure under differentiated subsidence, (ii) assessing impacts on agriculture and, (iii) integration of costs and benefits per potential mea- 

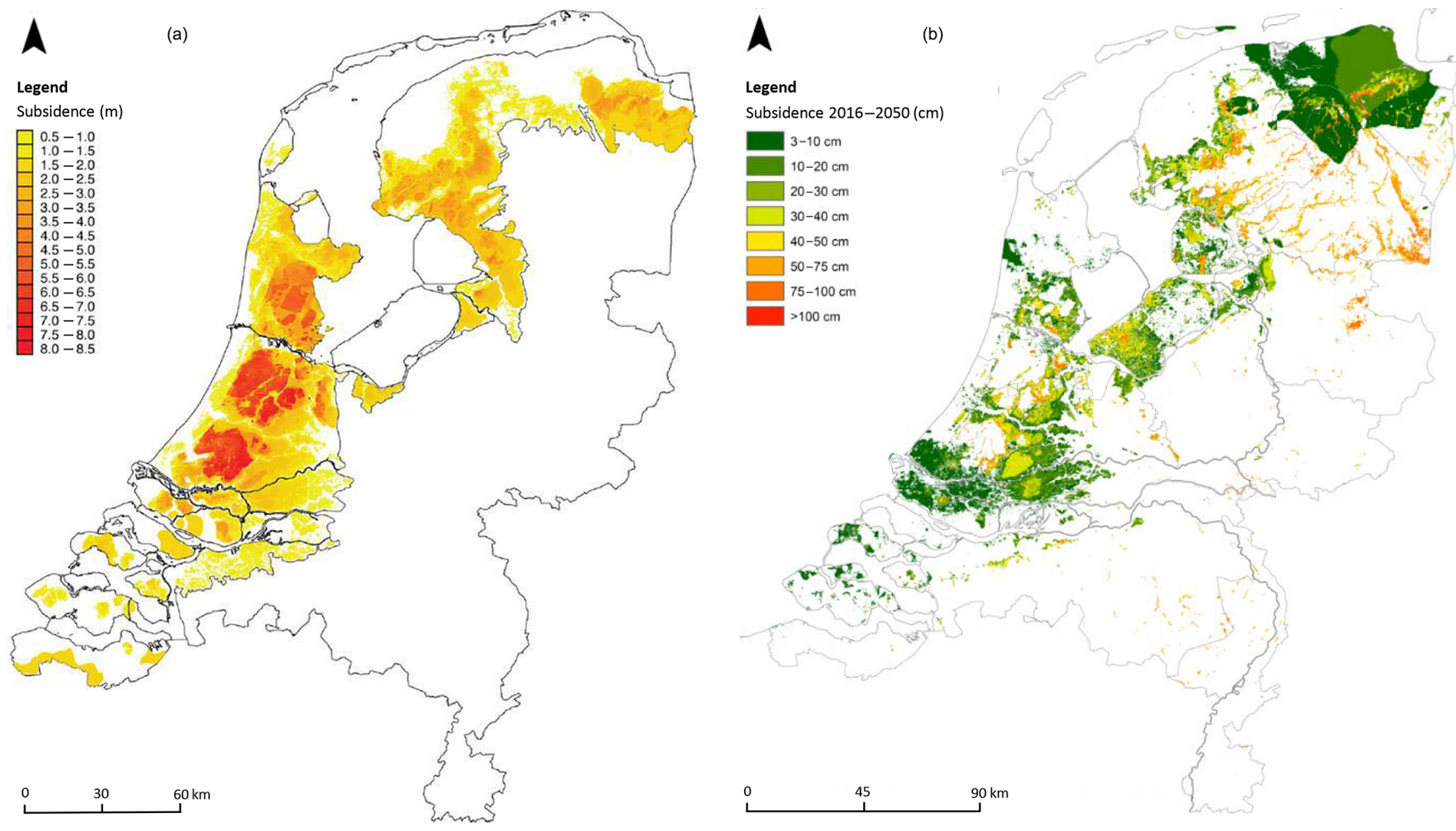

Figure 1. (a) Land subsidence over the last 1000 years in the coastal peat lands of the Netherlands due to drainage, loading and peat mining (Erkens et al., 2016). (b) Prediction of the amount of land subsidence for the coming decades, showing land subsidence of soft soils, salt mining and gas extraction (Erkens et al., 2017).

sure (implementation costs, damage, social/health risks, GHG emissions);

4. develop effective and legitimate subsidence mitigation strategies, making use of the findings on drivers of subsidence and its socio-economic impact, supported by governance approaches and the necessary financial and legal frameworks to enable successful selection and implementation of these future-proof, context-sensitive management strategies for intensively used agro-urban delta plains.

\subsection{Program set-up}

The program consists of four scientific work packages and a fifth one on knowledge utilization. To enable direct use of results in policy making, the program covers the $6 \mathrm{M}$ approach in dealing with subsidence (Erkens and Stouthamer, 2020): subsidence measuring and analysis of mechanisms, quantifying impacts, deliberating measures and evaluating performance (Figs. 2-3). Each work package delivers knowledge of direct use to activities of the linked step in the policy cycle.

\subsubsection{Work packages}

WP1-Measuring and monitoring of subsidence rates at local and regional scales: will utilize InSAR satellite-

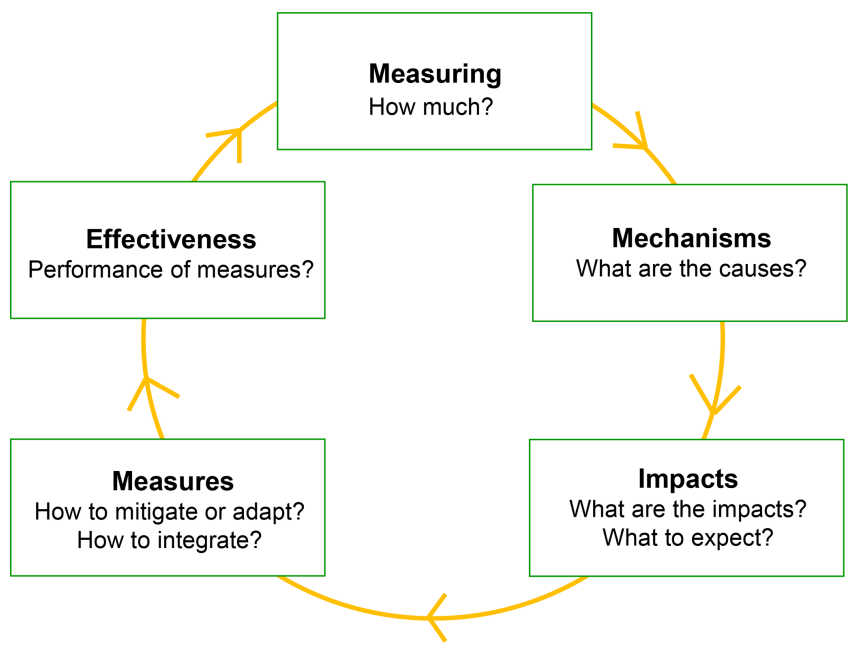

Figure 2. The program framework and approach link up with the policy cycle to ensure uptake of the research results in policy and to facilitate implementation of effective measures (after: Erkens and Stouthamer, 2020).

based radar technology at high spatio-temporal resolutions and integrate this with geophysical modelling techniques, to disentangle total ground movement into shallow and deep and anthropogenic and natural contributions, including sea-level rise related subsidence 
Living on soft soils program

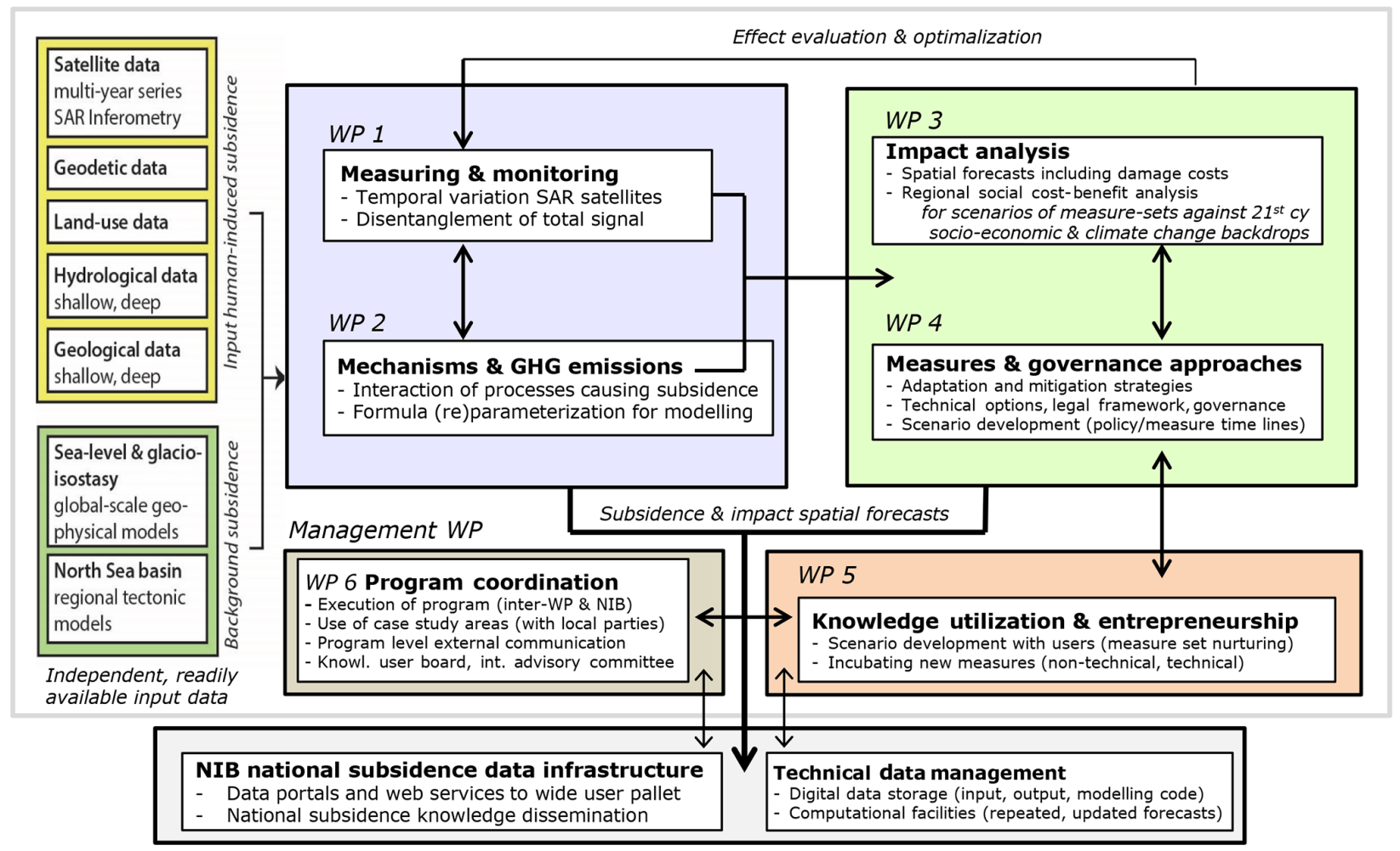

Figure 3. Program structure. We will follow an iterative approach whereby insights from the different work packages feed into one another and enrich the knowledge needs addressed by other WPs.

components. InSAR techniques will be developed to monitor soft soil subsidence in agricultural and urban areas, with disentangled signals of groundwater, salt and hydrocarbon extractions (inverse modelling) and glacioand hydro-isostasy (GIA modelling, gravimetry, background regional relative sea-level rise).

WP2 - Mechanisms and GHG emissions: aims to unravel, better understand and quantify the interacting subsidence processes such as peat oxidation with associated GHG emissions, compaction, shrinkage, creep, and examine the environmental impact of subsidence mitigation measures. It includes parameterization and calibration of process models used to analyze and forecast subsidence.

WP3 - Impact analysis: focusses on predictive modelling by integration of process models in one numerical framework to predict subsidence under different management scenarios, and the development of new methods to estimate subsidence-related damage to infrastructure, buildings and agriculture, besides GHG emissions, as input for an socio-economic cost-benefit analysis (SCBA, converting $\mathrm{mm} \mathrm{yr}^{-1}$ to EUR $\mathrm{yr}^{-1}$ ). This work package has a focus on numerical model development and (big) data analyses and includes geomod- elling, material science research and economic modeling.

WP4 - Measures and governance approaches: aims to (i) identify suitable mitigation, adaptation and compensation measures, (ii) develop economic and financial tools aiming at supporting parties to carry the costs of damage and/or implementation of measures, (iii) provide recommendations for strengthening governance capacities for dealing with existing and new challenges (e.g. drought, salinization due to sea-level rise) in water management and spatial planning, (iv) develop equitable and legitimate legal frameworks to effectively implement new strategies of dealing with subsidence.

WP5 - Knowledge utilization and entrepreneurship: will translate the scientific results to practice in close cooperation with knowledge-users and entrepreneurs; design and development of innovative mitigation and management strategies under different scenarios of socioeconomic and climatic circumstances.

Knowledge utilization is an integral part of this research program. Knowledge-users are part of the consortium and stakeholders in case study areas will be actively involved. 


\subsubsection{Expected deliverables}

As results, the program is expected to deliver:

1. Technology for satellite-based subsidence monitoring, interpretation and use in forecasting (WP1);

2. Improved empirical understanding and knowledge integration on individual processes and their interactions and feedbacks driving soft soil subsidence, including upscaled calibration allowing to implement it in spatial models (WP2), and operationalize it for damage quantifications and cost-benefit analysis (WP3);

3. Open-source spatial subsidence models and forecast maps (scenarios), that will support decision-making and policy-design (WP3-4), developed aligned with existing (TNO-GSN) and newly launched (NIB) national data infrastructure, to feed, host and reiterate such modelling.

4. Technical and economic measures to mitigate and adapt to subsidence.

5. Governance and legal strategies that facilitate the implementation of proposed measures: policy and decision support tools to manage subsidence.

Data availability. No data sets were used in this article.

Author contributions. ES wrote the paper. GE commented on an earlier draft of this paper. This paper is based on the research proposal "Living on Soft Soils: Subsidence and Society" (NWO-NWA) that was initiated and coordinated by ES. All authors of this paper contributed to the design and writing of the research proposal.

Competing interests. The authors declare that Gilles Erkens is member of the editorial board of this special issue but has not reviewed this paper, nor has he influenced the publication decision process.
Special issue statement. This article is part of the special issue "TISOLS: the Tenth International Symposium On Land Subsidence - living with subsidence". It is a result of the Tenth International Symposium on Land Subsidence, Delft, the Netherlands, 17-21 May 2021

Financial support. The Dutch National Scientific Research Program on Land Subsidence: Living on Soft Soils - Subsidence and Society will be primarily funded by the Dutch scientific organization (NWO-NWA, grant: NWA.1160.18.259), and will be cofunded and supported by 17 consortium partners (see above).

\section{References}

Erkens, G. and Stouthamer, E.: The $6 \mathrm{M}$ approach to land subsidence, Proc. IAHS, this volume, 2020.

Erkens, G., Van der Meulen, M. J., and Middelkoop, H.: Double trouble: Subsidence and $\mathrm{CO}_{2}$ respiration due to 1,000 years of Dutch coastal peatland cultivation, Hydrogeol. J., 24, 551-568, 2016.

Erkens, G., Stafleu, J., and Van den Akker, J. J. H.: Bodemdalingvoorspellingskaarten van Nederland, versie 2017, Deltares rapport klimaateffectatlas, 2017.

Koster, K., Stafleu, J., Cohen, K. M., Stouthamer, E., Busschers, F. S., and Middelkoop, H.: 3D distribution of organic matter in coastal-deltaic peat: implications for subsidence and $\mathrm{CO}_{2}$ emissions by human induced peat oxidation, Anthropocene 22, 1-9, https://doi.org/10.1016/j.ancene.2018.03.001, 2018.

Van den Born, G. J., Kragt, F., Henkens, D., Rijken, B., Van Bemmel, B., and Van der Sluis, S.: Dalende bodems, Stijgende kosten, Report Planning Agency for the Environment (PBL), report nr. 1064, 93 pp., 2016. 